\title{
Variation in flexural, morphological, and biochemical leaf properties of eelgrass (Zostera marina) along the European Atlantic climate regions
}

Maike Paul ${ }^{1,3}$, Carmen B. de los Santos ${ }^{2}$

${ }^{1}$ Landscape Ecology and Environmental Systems Analysis, Institute of Geoecology, Technische Universität Braunschweig, Langer Kamp 19c, 38106 Brunswick, Germany.

${ }^{2}$ Centre of Marine Sciences of Algarve, University of Algarve, Gambelas, 8005-139 Faro, Portugal.

${ }^{3}$ Ludwig-Franzius-Institut, Leibniz Universität Hannover, Nienburger Str. 4, 30167 Hannover, Germany

* corresponding author. Email address: paul@lufi.uni-hannover.de (Maike Paul)

Maike Paul and Carmen B. de los Santos contributed equally to data analysis and preparation of the manuscript.

https://doi.org/10.1007/s00227-019-3577-2

Received 8 February 2019, Accepted 22 August 2019, Published online 17 September 2019. 


\begin{abstract}
Seagrasses need to withstand hydrodynamic forces; therefore, mechanical properties such as flexibility or breaking resistance are beneficial for survival. The co-variation of leaf breaking properties with biochemical traits in seagrasses has been documented, but it is unknown if the same patterns apply to leaf flexural properties. To interpret changes in the ecological function of seagrass ecosystems based on acclimation responses to environmental changes, it is necessary to understand the factors that affect flexural leaf properties. Here, morphological and flexural leaf properties of the perennial type of Zostera marina across different environmental conditions along European Atlantic climate regions are presented together with $\mathrm{C}: \mathrm{N}$ ratio and neutral detergent fibre content as descriptors of biochemical leaf composition. Eelgrass leaves from cold regions were $\sim$ threefold more elastic and $\sim$ tenfold more flexible, were also narrower (1.7-fold), and contained $\sim 1$.9-fold higher fibre content than from plants growing in warmer regions. Eelgrass also showed acclimation to local conditions such as seasonality, water depth, and hydrodynamic exposure. Leaves collected from exposed or shallower locations or during winter were more flexible, suggesting an avoidance strategy to hydrodynamic forcing, which is generally higher under those conditions. Flexural rigidity was almost equally controlled by bending modulus (35\%) and leaf thickness (37\%), indicating functional differences compared to leaf breaking described in the literature. Overall, the findings indicate that Zostera marina has a high flexural plasticity and high acclimation capacity to some climate change effects such as sea level rise and increase in storm frequency and intensity.
\end{abstract}




\section{Introduction}

Seagrass are flowering plants that evolved from terrestrial plants and adapted to underwater life (Den Hartog 1970). One of the adaptations they have to face are the strong forces imposed by waves and currents, which pose limitations to the seagrass growth through controlling the forces that leaves can withstand and thus influencing their distribution. Drag forces, the main form of these physical stresses, tend to pull the aquatic plants into the direction of the current (Vogel 1984) and can be reduced by minimising the area exposed, either by having a small size or by having larger forms with reconfiguration capability, such as flexible thin strap-like leaves. This so-called "avoidance strategy" (Vogel 1984; Puijalon et al. 2008; Bouma et al. 2005) was probably the most widespread foliar adaptation among the seagrass species (de los Santos et al. 2016a). Although many recent studies have advanced in the understanding of the seagrass leaf biomechanics (de los Santos et al. 2016a; La Nafie et al. 2013; Soissons et al. 2017), they focused on the variation of leaf breaking forces (i.e., their resistance to be broken), whereas little is known about the flexural properties of seagrass leaves, i.e., their capability to bend and thus reconfigure to avoid high drag forces.

Leaf flexibility determines how prone a leaf is to bending and can be estimated using the flexural rigidity ( $G$, Niklas 1992) that is defined as the resistance of a structure against bending deformation. It depends on the elasticity (the bending modulus) of the material of which the leaf is made of (e.g., more or less fibrous) as well as its geometry (i.e., width and thickness). That is, the more elastic or the thinner and narrower the leaf is, the more flexible it is. Understanding the contribution of these morphological and mechanical traits to the leaf flexural resistance is essential to understand likely trade-offs between having thick and more resistant leaves, favourable to resist breaking forces, or having thinner and more flexible leaves, favourable to reconfigure with the flow (Bouma et al. 2005; Puijalon et al. 2008). At the same time, various seagrass species have been shown to acclimate to environmental conditions, such as light, nutrients, $\mathrm{pH}$ and hydrodynamics, by changing their morphological and/or their biomechanical traits, either under experimental conditions (La Nafie et al. 2013; La Nafie et al. 2012; de los Santos et al. 2017), on a seasonal basis (de los Santos et al. 2013), among climate regions (de los Santos et al. 2016a) or across a latitudinal gradient (Soissons et al. 2017). In addition, mechanical traits related to the leaf breaking resistance are correlated with leaf biochemical traits such as elemental $(\mathrm{C}, \mathrm{N})$ and fibre contents, either among a wide variety of seagrass forms (de los Santos et al. 2016a; de los Santos et al. 2012) or within the same species over the leaf ontogeny stages (de los Santos et al. 2016b). These biochemical traits of the leaves, along with the mechanical traits, are important in ecosystem processes such as leaf litter decomposition, plant- 
herbivore interactions, and nutrient cycling (Read and Stokes 2006). Although advances have been made in understanding the co-variation of leaf breaking properties and biochemical traits in seagrasses (e.g., de los Santos et al. 2012), it is unknown if the same patterns apply to leaf bending properties. Given that mechanical properties underlie important ecological processes, understanding which leaf properties and abiotic factors contribute the most to flexural rigidity can help to interpret changes in the ecological function of seagrass ecosystems based on acclimation responses to local and global environmental changes.

Here, we aimed to investigate the morphological, flexural, and biochemical properties of Zostera marina, one of the most wide-ranging seagrass species, being circumglobal in the Northern hemisphere and occurring in temperate, cold, and polar climate regions. We expect this species to exhibit a significant variability in their leaf properties to acclimate to the environmental conditions to which perennial populations are exposed to. In particular, we focused on four questions: (1) How does flexural rigidity and other leaf traits vary across a range of temperate and cold climates? (2) How does flexural and associated morphological properties vary with abiotic drivers? (3) Which parameters dominate flexural rigidity? (4) How are leaf flexural properties correlated with leaf biochemical properties? To answer these questions, we measured an array of morphological, mechanical, and biochemical leaf traits in Zostera marina leaves of plants collected in locations subjected to different environmental conditions along four European Atlantic climate regions.

\section{Materials and methods}

\subsection{Sampling locations and biological material}

Subtidal meadows of the perennial type of Zostera marina were sampled in 6 locations across the four Köppen-Geiger climate classes (Beck et al. 2018) that exist along Europe's coasts from latitude 37 o to 580 (Fig. 1, Table 1). Locations covered all the temperate and cold climate classes in the studied latitudinal range: 1 location in Csa (temperate, dry summer, hot summer), 1 in Csb (temperate, dry summer, and warm summer), 2 in Cfb (temperate, no dry season, and warm summer), and 2 in Dfb (cold, no dry season, and warm summer). We focused on climate classes rather than on a mere latitudinal gradient, because the first approach includes information on climate parameters such as precipitation that would not have been available for the specific locations otherwise. Moreover, since climate classes are used in modelling of climate change scenarios (Beck et al. 2018), we thus expect our results to be more informative for future work in this format. 
For each location, water depth $(\mathrm{m})$ was measured in situ during sampling and maximum tidal range (m) was obtained from local tidal charts available at www.tide-forecast.com. Wind direction for spring/summer (April-September, representing the main growing season) conditions were estimated from wind statistics at the nearest weather station (www. windfinder.com) based on measured hourly wind direction (from 7 am to $7 \mathrm{pm}$ ) for 3-17 years prior to 2017 depending on data availability. Wind directions were then used to estimate fetch length available for generating wind-driven waves to the nearest $0.5 \mathrm{~km}$ from geographical maps. Salinity (psu) was measured in situ using conductivity gauges in the month of sampling. Mean daily air temperature $\left({ }^{\circ} \mathrm{C}\right)$ and sunshine hours per day (hours) data were obtained from the nearest World Meteorological Organization (WMO) station as mean values for July over the period 1990-2017, which the exception of the Vigo/Peinador station for Toralla location, where data were only available from 1996 onwards. Data on sunshine duration were not available for the Swedish station, so here, values were estimated from 10-year records (20072017) of hourly PAR measurements at the Kristineberg research station of the Sven Lovén Centre (University of Gothenburg). Sunshine was defined as PAR values $>769 \mu \mathrm{mol} \mathrm{s}^{-1} \mathrm{~m}^{-2}$ corresponding to Luxmeter values > $100 \mathrm{klx}$ (Domke 2014) which is defined as bright summer sunlight (DIN 50342:1985-02). While PAR and Luxmeter measurements operate in slightly different wave lengths with PAR measurements assessing radiation from 400-700 nm and Luxmeter capturing light in the range $550-600 \mathrm{~nm}$; however, for the assessment of sunlight, a robust conversion is available (Domke 2014).

All meadows were sampled in summer (July 2017) and one of them (Culatra Island, Portugal, Csa) also in winter (December 2016) to assess the seasonality of leaf properties. At location, Neustadt (Germany, Cfb), shallow (1.5 m), and deep ( $5 \mathrm{~m}$ ) meadows were sampled to assess the variation with water depth, and the locations Gåsö and Blobasholmen represented sheltered (summer fetch $=0 \mathrm{~m}$ ) and exposed (summer fetch $=130 \mathrm{~km}$ ) locations in Sweden $(\mathrm{Dfb})$, respectively. In all cases, entire shoots of Zostera marina were collected ( $\mathrm{n}=26-34$ in each location), either by SCUBA diving or by snorkelling, in the middle of the meadow to avoid likely edge effects. Seagrass shoots were transported to the laboratory in seawater and tested within $48 \mathrm{~h}$ from collection, a proven valid time to assess mechanical properties in seagrasses (de los Santos et al. 2016b). 


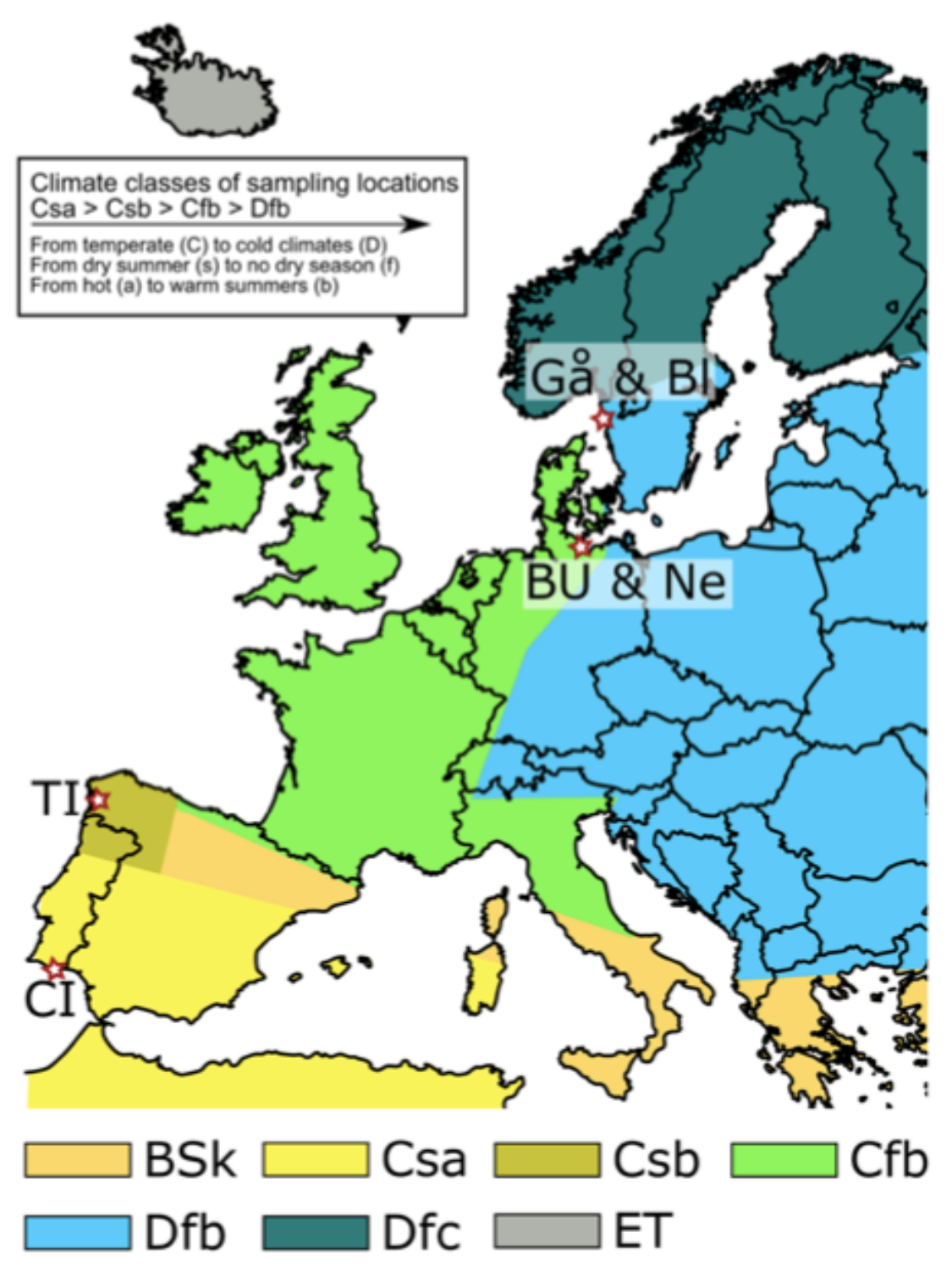

Fig. 1. Map indicating the locations and climate classes, where Zostera marina populations were sampled: CI: Culatra Island (Portugal, Csa); TI: Toralla Island (Spain, Csb); BU: Brodtener Ufer (Germany, Cfb); Ne: Neustadt (Germany, Cfb); Gå: Gåsö (Sweden, Dfb); Bl: Blobasholmen (Sweden, Dfb). Köppen-Geiger climate classes are (Beck et al. 2018): BSk (arid, steppe, cold), Csa (temperate, dry summer, hot summer), Csb (temperate, dry summer, warm summer), Cfb (temperate, no dry season, warm summer), Dfb (cold, no dry season, warm summer), Dfc (cold, no dry season, cold summer), ET (Polar, Tundra). Map base by freevector.com, distribution of climate classes simplified after Beck et al. (2018). 
Table 1. Description of the sampling locations. Köppen-Geiger climate classes are (Beck et al. 2018): Csa (temperate, dry summer, hot summer), Csb (temperate, dry summer, warm summer), Cfb (temperate, no dry season, warm summer), Dfb (cold, no dry season, warm summer).

\begin{tabular}{|c|c|c|c|c|c|c|c|c|c|}
\hline Location & Climate & Latitude $\left(^{\circ}\right)$ & Longitude $\left({ }^{\circ}\right)$ & $\begin{array}{l}\text { Mean depth } \\
\text { (m) }\end{array}$ & $\begin{array}{l}\text { Maximum } \\
\text { tidal } \\
\text { range }(\mathrm{m})\end{array}$ & $\begin{array}{l}\text { Fetch length, } \\
\text { summer }(\mathbf{k m})\end{array}$ & $\begin{array}{l}\text { Mean } \\
\text { salinity } \\
\text { (ppt) }\end{array}$ & $\begin{array}{l}\text { Mean air } \\
\text { temperature* } \\
\left({ }^{\circ} \mathrm{C}\right)\end{array}$ & $\begin{array}{l}\text { Sunshine per } \\
\text { day* (hours) }\end{array}$ \\
\hline Culatra Island (CI), Portugal & Csa & 37.00 & -7.83 & 3.0 & 3.11 & 3 & 36.5 & 24.4 & 11.7 \\
\hline Toralla Island (TI), Spain & $\mathrm{Csb}$ & 42.20 & -8.80 & 4.1 & 3.87 & 0 & 35.5 & 19.8 & 9.4 \\
\hline Brodtener Ufer (BU), Germany & $\mathrm{Cfb}$ & 53.98 & 10.88 & 5.0 & 0.03 & 94 & 15.0 & 18.0 & 7.7 \\
\hline Neustadt (Ne), Germany & $\mathrm{Cfb}$ & 54.08 & 10.79 & 1.5 and 5.0 & 0.02 & 2 & 12.8 & 18.0 & 7.7 \\
\hline Gåsö (Gå), Sweden & $\mathrm{Dfb}$ & 58.24 & 11.40 & 1.9 & 0.34 & 0 & 26.1 & 17.2 & 6.1 \\
\hline Blobasholmen (Bl), Sweden & Dfb & 58.25 & 11.45 & 1.3 & 0.34 & 130 & 25.2 & 17.2 & 6.1 \\
\hline
\end{tabular}

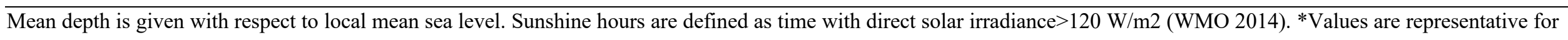
July. 


\subsection{Determination of flexural and morphological leaf traits}

Flexural rigidity $(E I)$ describes the resistance of a structure against bending deformation: the higher the flexural rigidity, the stiffer the structure is, so the harder it will be to bend (less flexible). EI is computed as the product of the Young's modulus of elasticity in bending $E$ (named bending modulus hereafter) and the second moment of area (I). The bending modulus $E$ is a material property, that is, it is invariant with the size of the structure, and the higher the modulus, the less elastic the material is. The second moment of area $I$ is a geometrical property which reflects how the area of a structure is distributed with regard to an arbitrary axis, and it defines the "efficiency" of a cross-sectional shape to resist bending caused by loading: the higher $I$, the higher the efficiency to resist bending forces. The second moment of area is the product of two important dimensional traits in a leaf, the width, and thickness. For a rectangular cross-sectional leaf area, the second moment of area varies linearly with leaf width, but by a power of three with leaf thickness. It is important to distinguish between the bending modulus, which defines how elastic a material is and which is independent of the size (depends on the materials the leaf is made of), and the flexural rigidity, which defines how flexible a structure is and which is dependent of the modulus of elasticity and the dimensions of the structure (thickness and width).

Flexural tests were conducted on the third leaf of each seagrass shoot (to avoid leaf age variability, de los Santos et al. 2016b), after cutting the leaf blade at the ligule to exclude the leaf sheath. Excess surface water was removed with a paper towel before testing. Bending modulus $\mathrm{E}\left(\mathrm{N} \mathrm{mm}^{-2}\right)$ was determined following the method by Henry (2014), which is an adaptation of the Pierce's cantilever test to measure the flexural rigidity of thin flexible macrophyte blades. The method is ultimately based on the principles of the bending theory and consists of allowing the leaves to bend to a $45^{\circ}$ angle $(\theta)$ on a purpose-built metal structure (see Henry 2014 for details). The blade length required to reach that angle $l_{c}(\mathrm{~cm})$, the total leaf length $l s(\mathrm{~cm})$, the leaf width $b(\mathrm{~mm})$, and the thickness $t$ $(\mathrm{mm})$ were measured using a ruler $\left(l_{c}\right.$ and $\left.l_{s}, \pm 1 \mathrm{~mm}\right)$, digital calliper $(b, \pm 0.01 \mathrm{~mm})$, and micrometre screw $(\mathrm{t}, \pm 0.01 \mathrm{~mm})$. After the test, the blotted-dry wet weight $w_{w}(\mathrm{~g})$ of the tested leaf was measured on a precision balance $( \pm 0.001 \mathrm{~g})$ and the leaf was saved in wet conditions for further analysis (Section "Determination of leaf elemental and fibre contents"). For all tests, leaves were placed on the bending device with the adaxial side facing upwards. Preliminary tests with seagrass leaves from the Swedish locations $(\mathrm{n}=62)$ revealed that $l_{c}$ was not affected by leaf orientation (paired $\mathrm{t}$ test, $\mathrm{t}_{61}=$ 0.53, $\mathrm{P}=0.6$, data not shown). The bending modulus (Eq. [1]) was estimated from the obtained parameters following equations by Henry (2014), with W being the weight per unit area in units of $\mathrm{N}$ 
$\mathrm{m}^{-2}\left[\mathrm{~W}=\mathrm{W}_{\mathrm{w}} \mathrm{g} /\left(1_{\mathrm{s}} \mathrm{b}\right)\right.$, where $\mathrm{g}\left(\mathrm{m} \mathrm{s}^{-2}\right)$ is the acceleration due to gravity]. Finally, flexural rigidity $\mathrm{G}$ $\left(\mathrm{N} \mathrm{mm}^{2}\right.$, Eq. [2]) was estimated from $\mathrm{E}\left(\mathrm{N} \mathrm{mm}^{-2}\right)$ and the second moment of area $\mathrm{I}\left(\mathrm{mm}^{4}\right.$, Eq. [3]). All calculations assumed leaves to have constant rectangular planforms and cross-sectional areas:

$$
\begin{aligned}
& E=\frac{12 W l_{c}^{3}}{t^{3}}\left(\frac{\cos \left(\frac{\theta}{2}\right)}{8 \tan (\theta)}\right) \\
& G=E I \\
& I=\frac{1}{12} b t^{3}
\end{aligned}
$$

\subsection{Determination of leaf elemental and fibre contents}

After measuring the leaf biomechanical properties, epiphyte-cleaned leaves from each location were dried $\left(60{ }^{\circ} \mathrm{C}, 48 \mathrm{~h}\right)$ and pulverized in a ball grinder. Subsamples of dried biomass $(\mathrm{n}=3$ for each location) were then used for determination of total $\mathrm{C}$ and $\mathrm{N}$ contents (\% dry weight) using an elemental analyser (Elementar, Vario EL III). C:N ratio was calculated based on dry biomass. A second subsample was used to determine the neutral detergent fibre (NDF) content following the method of van Soest et al. 1991) (with minor modifications, de los Santos et al. 2012). This procedure gives the neutral detergent fibre content as the difference in dry biomass after digestion. Replicate samples $\left(\mathrm{n}=4,20-30 \mathrm{mg}\right.$ each) of dry biomass were heated to boiling $\left(100^{\circ} \mathrm{C}\right)$ in $2 \mathrm{~mL}$ of neutral detergent (Ankom FND20C) for $1 \mathrm{~h}$, followed by repetitive washings of the pellet after centrifuging $(2500 \times \mathrm{g}, 5 \mathrm{~min})$ with distilled water $(\times 2)$, ethanol $(\times 1)$ and acetone $(\times 2)$. The final pellet, free of noncell wall components and chlorophyll, was dried overnight in an oven at $60{ }^{\circ} \mathrm{C}$ and weighed again. The amount of fibre for each sample was obtained by the difference in mass and expressed as fibre percentage of dry biomass (\% or $\mathrm{g}$ of fibre per $100 \mathrm{~g}$ of dry biomass). In seagrasses, fibre content roughly represents the amount of cellulose, hemicellulose, and, when present, lignin (Kuo and Den Hartog 2006).

\subsection{Data analysis and statistics}

Data are presented as mean \pm standard error of the mean (SE) if not otherwise stated. The extent of variation of each leaf trait among locations was calculated as the coefficient of variation (\%), whereas its within-location variation was computed as the mean of the $\mathrm{CV}$ of each leaf trait in that location. 
Normality and homoscedasticity of the leaf properties data were confirmed using Shapiro-Wilk and Levene tests, respectively. Differences among locations and climates were analysed using one-way ANOVA (F) with locations or climate classes as fixed factor, respectively, followed by Tukey's multiple comparison test when differences among factor levels were observed. In addition, stepwise linear regression models were applied to the summer data across latitudes but did not yield conclusive results (data not shown). Differences in leaf traits between (a) deep and shallow stations at location Neustadt (Cfb), (b) winter and summer seasons at location Culatra (Csa), and (c) exposed and sheltered locations in Sweden (Gåsö being sheltered and Blobasholmen being exposed, Dfb) were analysed by unpaired t test $(\mathrm{t})$. When parametric assumptions were not satisfied even after $\log 10$ transformation, comparison between pairs of locations or among all the locations were performed by non-parametric Wilcoxon (W) or Kruskal-Wallis rank sum test (H) followed by post hoc Dunn's test when differences were observed, respectively.

To evaluate the contribution of different leaf traits (leaf width $b$, leaf thickness $t$, and bending modulus $E$ ) on the flexural rigidity $(G)$, variance partitioning was performed as described by de los Santos et al. (2016a). In brief, the flexural rigidity $(G)$ is denoted as the sum of the covariances between each component $\left(E, t\right.$, and $\left.3^{*} b\right)$, and when the covariance of each component is taken as a proportion of the variance of the flexural rigidity, the relative contribution of each component can be obtained. A principal component analysis (PCA), based on correlation matrix, was conducted with the mean values of $Z$. marina leaf traits in summer (morphological, flexural, and biochemical) and the abiotic variables in Table 1 to investigate the association between climate classes and variables, and among variables. The variables in the PCA were standardised and scaled to unit variance before the analysis. A critical $\alpha$ level of 0.05 was used for all hypotheses tested. Statistical analyses were done using R programming software (v 3.5.1. R Core Team 2018).

\section{Results}

\subsection{Variation among locations and with climate classes}

Leaf length (third leaf) of summer Zostera marina varied threefold among locations, ranging from ca. $18 \mathrm{~cm}$ at the two locations with a mean depth $\leq 1.5 \mathrm{~m}$ to $>50 \mathrm{~cm}$ in Brodtener Ufer with a mean water depth of $5 \mathrm{~m}$ (Tables 2 and 3). Leaf thickness and width varied 2.5- and 1.7-fold among locations, respectively, and differed statistically among them (Tables 2 and 3). The bending modulus of the leaves also exhibited a high among-location variability, with values in the range of ca. 30-37 
$\mathrm{N} \mathrm{mm}{ }^{-2}$ for the majority of the locations except for the two southern most locations, which showed the highest values (ca. $75.5 \pm 4.7$ and $93.2 \pm 5.7 \mathrm{~N} \mathrm{~mm}^{-2}$, respectively; Table 2). Similarly, flexural rigidity of $Z$. marina leaves in summer varied tenfold among locations, from $0.35 \pm 0.052 \mathrm{~N} \mathrm{~mm}^{2}$ in Neustadt (shallow, Cfb) to $3.77 \pm 0.21 \mathrm{~N} \mathrm{~mm}$ in Culatra (Csa; Tables 2 and 3). In general, both morphological and flexural leaf traits showed a high intra-location variation (Table 2). Biochemical leaf traits differed significantly among locations and showed little within-location variability (Tables 2 and 3$)$.

Leaves of Z. marina from locations with a temperate climate with dry season (classes Csa and Csb) presented wider and less elastic leaves, but not necessarily stiffer leaves, than those from temperate and cold climates with no dry season (Cfb and Dfb) (Fig. 2, Table 3). Leaf thickness and length varied significantly among climate classes but did not show any clear pattern with the climate gradient. Except for nitrogen content, biochemical leaf traits differed among climate classes (Fig. 2, Table 3), with a notorious gradient for leaf fibre content, which significantly increased from $28.2 \pm 0.6 \% \mathrm{dw}$ in temperate dry hot summer (Csa) locations to $52.8 \pm 1.5 \%$ dw in cold no dry warm summer (Dfb).

\subsection{Variation with local conditions}

Eelgrass leaves at the southernmost station (Culatra Island, Portugal, Csa) were slightly less elastic, less flexible, and shorter in summer than in winter, with leaf thickness not being affected by seasonality (Fig. 3a, Table 3). Leaf properties of Z. marina varied also with water depth at the Neustadt location $(\mathrm{Cfb})$, with plants from the deep location having longer, thicker, wider, and more rigid leaves, but the same elasticity than those from the shallow location (Fig. 3b, Table 3). Regarding the comparison between sheltered and exposed locations in Sweden (Dfb), leaves tended to be shorter, thinner, narrower, and more flexible in the plants from the exposed location, although the bending modulus did not vary between the two meadows (Fig. 3c, Table 3).

\subsection{Variance partitioning}

Variance partitioning analysis showed that bending modulus and leaf thickness contributed almost equally to the variation in the flexural rigidity of the leaves in Zostera marina within each location. The theoretical contributions of the bending modulus ranged from $74 \%$ at the northernmost location (Blobasholmen, Dfb) to $7 \%$ in the westernmost location (Toralla, Csb), and had a mean of $46 \%$ (Fig. 4). Leaf thickness as the second important trait explaining the intra-location variation in flexural 
rigidity had a contribution ranging from 74 to $16 \%$ and a mean of $40 \%$. When all the data were pooled to assess the relative contribution of each leaf trait to the among-location variation in flexural rigidity, the contribution of bending modulus and thickness was, again, fairly similar (35\% and 37\%, respectively) and that of leaf width was a little bit lower (27\%, Fig. 4).
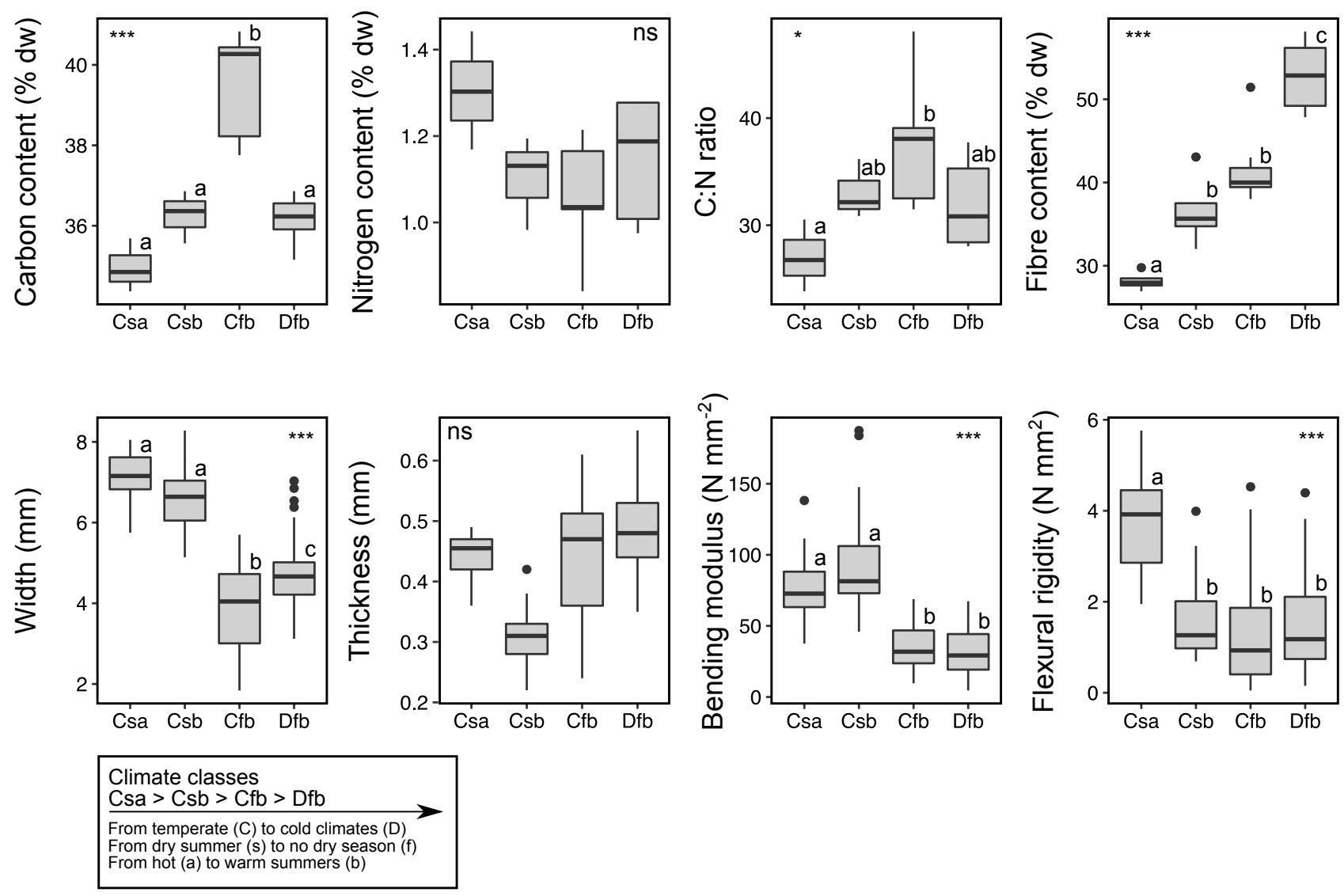

Fig. 2. Biochemical, morphological and flexural properties of Zostera marina leaves in summer from four climate classes (Köppen-Geiger classes): Csa (temperate, dry summer, hot summer), Csb (temperate, dry summer, warm summer), Cfb (temperate, no dry season, warm summer), Dfb (cold, no dry season, warm summer). Boxplot bar is median; box is interquartile (IQR) range; whiskers are maximum and minimum values within the $1.5 \times \mathrm{IQR}$ of the hinge, and dots are outliers. Statistical significance ( $\mathrm{p}$ value: $*<0.05, * *<0.01, * * *<0.01$, ns not significant) is given in each panel for the 1way ANOVA or Kruskal-Wallis test conducted in each case. 
Table 2. Summary of morphological, biochemical and mechanical leaf traits of seagrass Zostera marina at the sampled locations.

\begin{tabular}{|c|c|c|c|c|c|c|c|c|c|c|}
\hline Leaf trait & $\begin{array}{l}\text { Culatra } \\
(\mathbf{w} ; n=30)\end{array}$ & $\begin{array}{l}\text { Culatra } \\
(s ; n=26)\end{array}$ & $\begin{array}{l}\text { Toralla } \\
(n=34)\end{array}$ & $\begin{array}{l}\text { Brodtener } \\
\text { Ufer } \\
(n=31)\end{array}$ & $\begin{array}{l}\text { Neustadt } \\
\text { (deep; } \\
n=\mathbf{3 0})\end{array}$ & $\begin{array}{l}\text { Neustadt } \\
\text { (shallow; } \\
n=31 \text { ) }\end{array}$ & $\begin{array}{l}\text { Gåsö } \\
(n=32)\end{array}$ & $\begin{array}{l}\text { Blobasholme } \\
(n=30)\end{array}$ & $\begin{array}{l}\text { CV (\%) } \\
\text { among- }\end{array}$ & $\begin{array}{l}\mathrm{CV}(\%) \\
\text { within- }\end{array}$ \\
\hline Length, $l(\mathrm{~cm})$ & $45.5 \pm 1.3$ & $24.4 \pm 1.1$ & $32.0 \pm 1.1$ & $56.2 \pm 2.3$ & $46.8 \pm 2.1$ & $18.3 \pm 0.8$ & $29.8 \pm 1.0$ & $18.2 \pm 0.7$ & 44.7 & 22.5 \\
\hline Thickness, $t$ (mm) & $0.45 \pm 0.01$ & $0.44 \pm 0.01$ & $0.31 \pm 0.01$ & $0.49 \pm 0.01$ & $0.51 \pm 0.01$ & $0.34 \pm 0.01$ & $0.52 \pm 0.01$ & $0.45 \pm 0.01$ & 19.1 & 11.6 \\
\hline Width, $b(\mathrm{~mm})$ & $6.30 \pm 0.10$ & $7.09 \pm 0.13$ & $6.61 \pm 0.12$ & $4.40 \pm 0.11$ & $4.57 \pm 0.11$ & $2.81 \pm 0.09$ & $5.15 \pm 0.15$ & $4.34 \pm 0.09$ & 19.2 & 13.1 \\
\hline $\mathrm{C}$ content $(\% \mathrm{dw})$ & $34.3 \pm 0.3$ & $35.0 \pm 0.4$ & $36.3 \pm 0.4$ & $38.0 \pm 0.1$ & $40.0 \pm 0.3$ & $40.6 \pm 0.1$ & $36.2 \pm 0.2$ & $36.1 \pm 0.5$ & 5.8 & 1.4 \\
\hline $\mathrm{N}$ content $(\% \mathrm{dw})$ & $1.85 \pm 0.12$ & $1.30 \pm 0.08$ & $1.10 \pm 0.06$ & $1.19 \pm 0.01$ & $1.03 \pm 0.01$ & $1.00 \pm 0.09$ & $1.28 \pm 0.00$ & $1.02 \pm 0.04$ & 11.2 & 6.5 \\
\hline $\mathrm{C}: \mathrm{N}$ ratio & $18.7 \pm 1.0$ & $27.0 \pm 1.9$ & $33.1 \pm 1.6$ & $32.0 \pm 0.3$ & $38.7 \pm 0.3$ & $41.4 \pm 3.6$ & $28.3 \pm 0.2$ & $35.6 \pm 1.4$ & 15.5 & 6.7 \\
\hline Fibre content $(\% \mathrm{dw})$ & $37.3 \pm 1.1$ & $28.2 \pm 0.6$ & $36.6 \pm 2.3$ & $44.6 \pm 2.3$ & $39.6 \pm 0.6$ & $39.4 \pm 0.5$ & $48.8 \pm 0.5$ & $56.7 \pm 0.5$ & 21.8 & 5.2 \\
\hline $\begin{array}{l}\text { Bending modulus, } E \\
\left(\mathrm{~N} \mathrm{~mm}^{-2}\right)\end{array}$ & $53.9 \pm 4.7$ & $75.5 \pm 4.7$ & $93.2 \pm 5.7$ & $30.9 \pm 2.3$ & $36.2 \pm 2.6$ & $36.9 \pm 2.9$ & $32.1 \pm 2.9$ & $30.6 \pm 2.8$ & 53.3 & 41.7 \\
\hline $\begin{array}{l}\text { Flexural rigidity, } G \\
\left(\mathrm{~N} \mathrm{~mm}^{2}\right)\end{array}$ & $2.55 \pm 0.25$ & $3.77 \pm 0.21$ & $1.51 \pm 0.13$ & $1.43 \pm 0.16$ & $1.86 \pm 0.17$ & $0.35 \pm 0.05$ & $2.00 \pm 0.19$ & $1.01 \pm 0.11$ & 62.4 & 54.3 \\
\hline
\end{tabular}

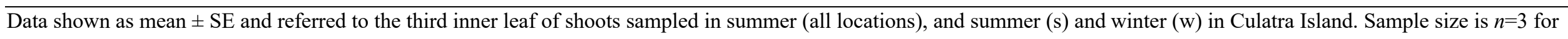

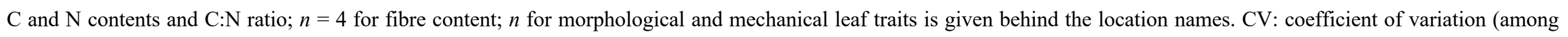
locations, and averaged CV within-location, only for summer. 
Table 3. Results of the statistics tests performed to investigate differences in leaf traits of Zostera marina among locations and climate classes, based on 1-way ANOVA test (F-statistic) or Kruskal-Wallis test (H-statistic), and between pairs of locations to assess the differences between seasons (winter vs summer), depth level (shallow vs deep) and exposure to waves (sheltered vs exposed), based on t test (t) or Wilcoxon rank sum test (W).

\begin{tabular}{|c|c|c|c|c|c|}
\hline Leaf variable & Factor: locations & Factor: climate classes & Factor: season & Factor: depth & Factor: exposure \\
\hline Length & $F_{6,207}=102.3, P<0.001$ & $H_{3}=37.2, P<0.001$ & $t_{55}=-12.1, P<0.001$ & $W_{60}=918, P<0.001$ & $t_{61}=-8.9, P<0.001$ \\
\hline Thickness & $F_{6,207}=94.1, P<0.001$ & $H_{3}=72.8, P<0.001$ & $t_{55}=-0.5, P=0.634$ & $W_{60}=917, P<0.001$ & $t_{61}=-5.3, P<0.001$ \\
\hline Width & $F_{6,207}=157.1, P<0.001$ & $H_{3}=133.3, P<0.001$ & $t_{55}=4.8, P<0.001$ & $W_{60}=911, P<0.001$ & $t_{61}=-4.8, P<0.005$ \\
\hline C content & $F_{6,14}=44.9, P<0.001$ & $F_{3,17}=25.2, P<0.001$ & - & - & - \\
\hline $\mathrm{N}$ content & $F_{6,14}=5.7, P<0.01$ & $F_{3,17}=2.5, P=0.09$ & - & - & - \\
\hline $\mathrm{C}: \mathrm{N}$ ratio & $F_{6,14}=8.9, P<0.001$ & $F_{3,17}=4.4, P<0.05$ & - & - & - \\
\hline Fibre content & $F_{6,14}=48.2, P<0.001$ & $F_{3,24}=42.9, P<0.001$ & - & - & - \\
\hline Bending modulus & $F_{6,207}=34.7, \mathrm{P}<0.001$ & $H_{3}=114.9, P<0.001$ & $t_{55}=3.3, P<0.01$ & $t_{60}=-0.18, P=0.85$ & $t_{61}=-0.37, P=0.71$ \\
\hline Flexural rigidity & $F_{6,207}=50.2, P<0.001$ & $H_{3}=60.9, P<0.001$ & $t_{55}=3.7, P<0.001$ & $t_{60}=10.9, P<0.001$ & $t_{61}=-4.5, P<0.001$ \\
\hline
\end{tabular}

Degree of freedom are shown in subscripts and $P$ is the associated $p$ value. 


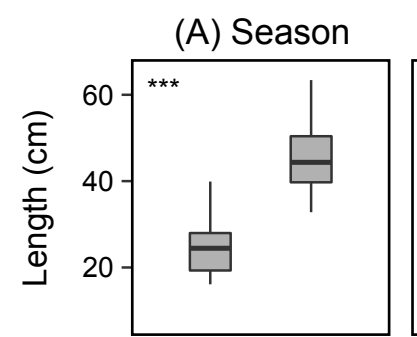

(B) Depth
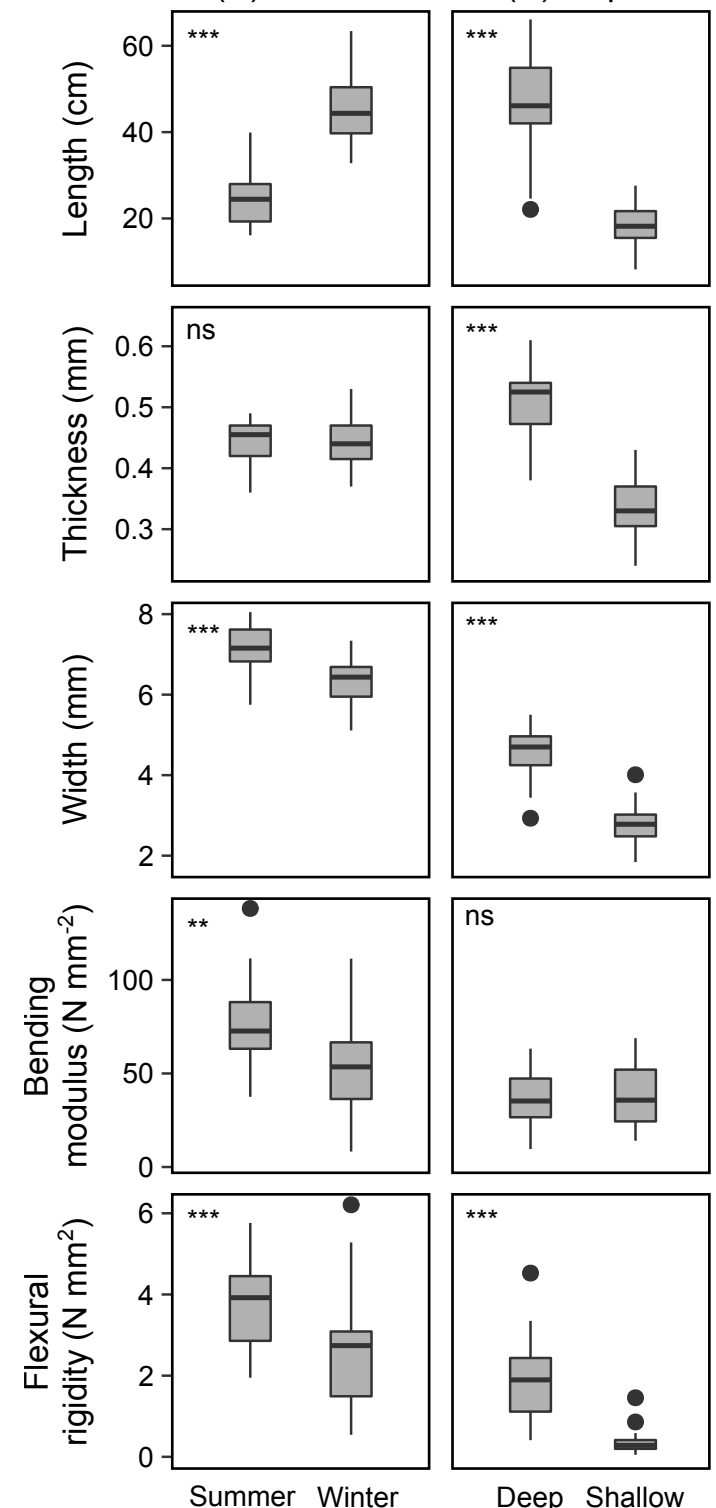
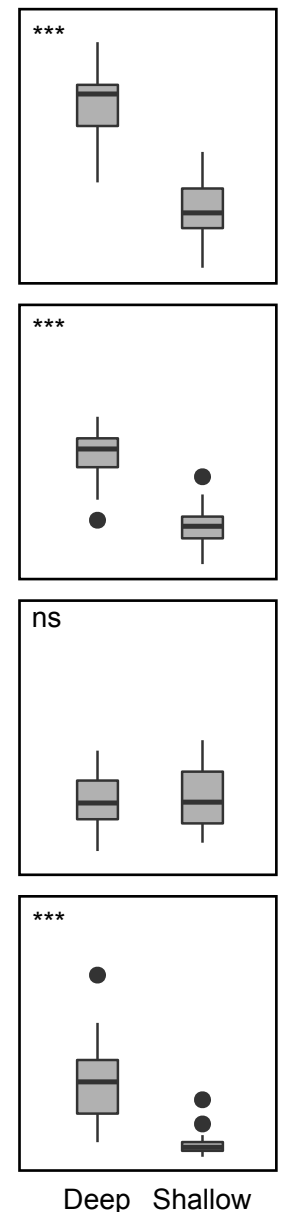

(C) Exposure
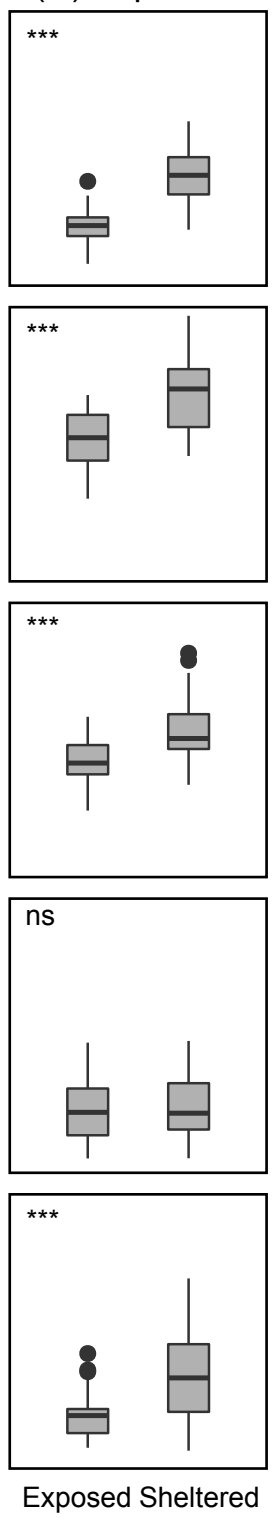

Fig. 3. Morphological (length, thickness and width) and flexural (bending modulus and flexural rigidity) properties of Zostera marina leaves under different environmental conditions: a seasons (winter vs summer) at Culatra Island (Portugal, Csa), b water depth (shallow vs deep meadows) at Neustadt (Germany, Cfb); and c hydro- dynamic exposure (sheltered vs exposed meadows) in Sweden (Gåsö being the sheltered loca- tion and Blobasholmen being the exposed one, Dfb). Boxplot bar is median; box is inter- quartile (IQR) range; whiskers are maximum and minimum values within the $1.5 \times$ IQR of the hinge, and dots are outliers. Statistical significance ( $p$ value: $*<0.05, * *<0.01$, $* * *<0.01, n s$ not significant) is given in each panel for the $t$ test or Wilcoxon rank sum test conducted in each case. 


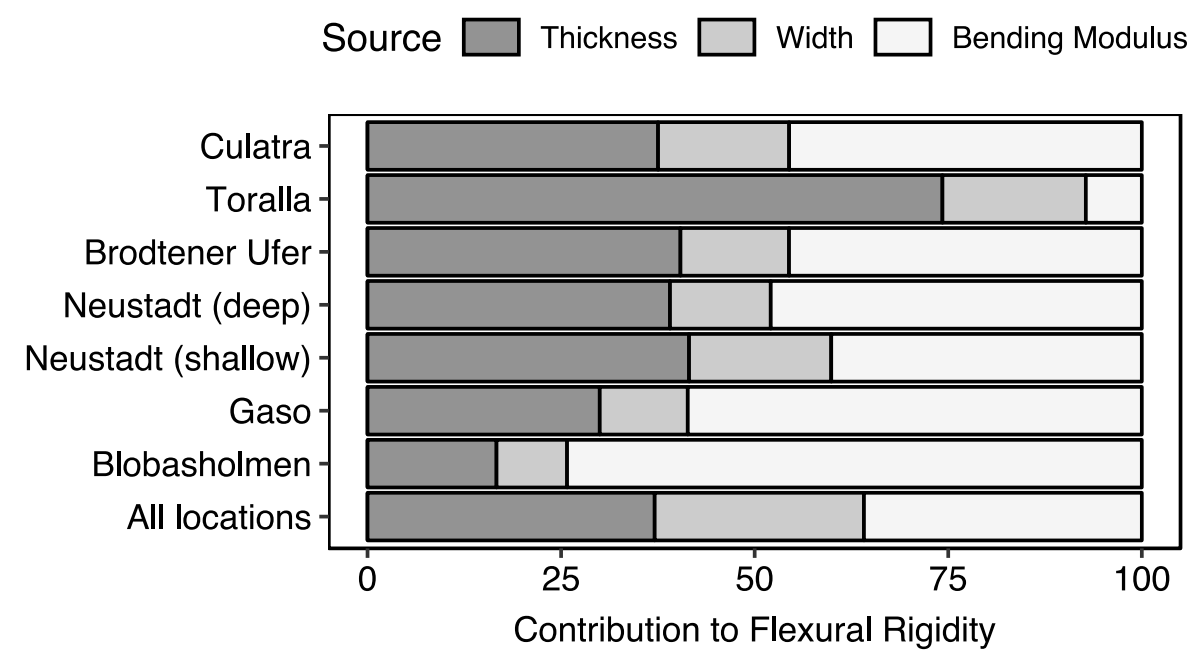

Fig. 4. Relative contribution of morphological leaf traits (thickness and width) and material property (bending modulus) to flexural rigidity for each sampling location in summer and for all locations together, based on the variance partitioning analysis.

\subsection{Correlation among leaf properties and climate conditions}

The first three components of the PCA analysis explained $87 \%$ of the variance. First principal component (PC1) had large associations with latitude and climate-related variables (air temperature and sunshine per day), location characteristics (tidal range and salinity), and some leaf traits (leaf width, fibre content, bending modulus, and flexural rigidity, Fig. 5). Thus, PC1 primarily measured latitudinal climate characteristics, clearly separating temperate with dry summers classes (Csa and $\mathrm{Csb}$ ) from the temperate and cold classes with no dry summers ( $\mathrm{Cfb}$ and Dfb, respectively; Fig. 5) and their association to flexural properties and fibre content. Secondarily, PC1 measured the strong correlation observed between leaf width and salinity. The second component (PC2) had large associations with thickness, nitrogen content, carbon content, and $\mathrm{C}: \mathrm{N}$ ratio, so this component primarily measured leaf biochemical traits in association with thickness (Fig. 5). The third component (PC3) associated with leaf length and water depth, so this component mainly represents morphological acclimation to water depth. Based on the PCA results, leaf flexural rigidity positively associated with $\mathrm{N}$ content and negatively to $\mathrm{C}: \mathrm{N}$ ratio and $\mathrm{C}$ content, while bending modulus negatively associated with fibre content (Fig. 5). 


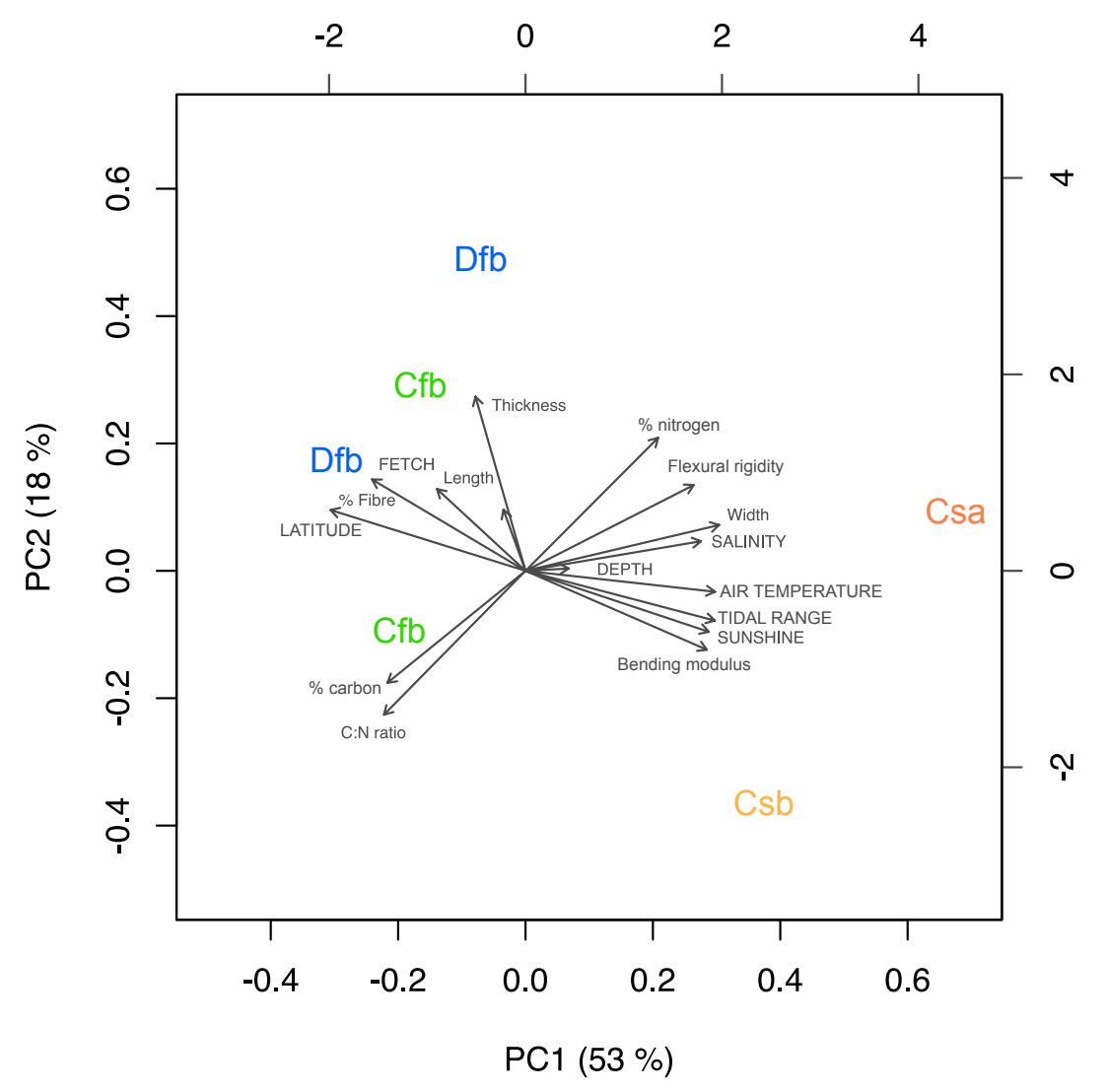

Fig. 5. Biplot of the principal component (PC) analysis with the projection of the assessed variables in Zostera marina populations during summer (arrows, uppercase for abiotic variables and lowercase for leaf traits) and the sampled locations labelled by climate class (Csa: temperate, dry summer, hot summer; Csb: temperate, dry summer, warm summer; $\mathrm{Cfb}$ : temperate, no dry season, warm summer; Dfb: cold, no dry season, warm summer). PC labels show the percentage of explained variance.

\section{Discussion}

We found a climate effect on the eelgrass leaves' flexural properties, which were $\sim$ threefold more elastic and $\sim$ tenfold more flexible in northern locations during summer season (Fig. 2). Climate effects on leaf mechanical properties have already been described for seagrasses. For instance, the leaf Young's modulus of elasticity in tension of Zostera noltei decreased towards northern latitudes, i.e., become more elastic in tension, across Europe in summer (Soissons et al. 2017). The similar findings for the modulus of elasticity in tension (Soissons et al. 2017) and bending (this study) suggest that the climatic drivers acting on mechanical properties may be the same for both types of deformation and that becoming more elastic in colder regions may be a general pattern among seagrass species, or at least for the genus Zostera. Climatic patterns have also been reported for tensile breaking forces (that is, the force that is needed to break a leaf when pulled), so that temperate species 
resisted higher forces than tropical species (de los Santos et al. 2016a). Overall, our findings and those already reported in the literature (Soissons et al. 2017; de los Santos et al. 2016a) suggest that mechanical traits of seagrass leaves vary with climate classes, with leaves being more resistant to be broken and more easily bent in colder climates. These two properties are, along with a high fibre content, desirable when high hydrodynamic forces act on the seagrasses, which generally increases with increasing latitude in Europe due to increased wind speeds and durations (Troen and Lundtang Petersen 1990). However, our data do not allow to identify whether the colder climate or the potentially increased hydrodynamic forcing at higher latitudes drive the observed increased flexibility. Given that other environmental variables such as nutrient content (La Nafie et al. 2012), light regime (La Nafie et al. 2013) and pH (de los Santos et al. 2017) can also affect the seagrass leaf mechanical properties, a more exhaustive assessment of environmental variables is needed to identify the drivers of the variability found in flexural rigidity among the climate classes sampled to further improve modelling of climate change scenarios.

We observed that eelgrass leaves acclimated morphologically to local conditions, in terms of seasonality, water depth, and hydrodynamic exposure (Fig. 3). The morphological acclimation of eelgrass with water depth (e.g., Meling-López and Ibarra-Obando 1999; Krause-Jensen et al. 2000) or with seasonality (e.g., Nienhuis and de Bree 1980; Orth and Moore 1986; Laugier et al. 1999) is well studied, but it is less for hydrodynamic exposure (but see for other species, e.g., Peralta et al. 2005). For instance, long leaves in deeper waters have been described as an acclimation mechanism to capture more light across the water column (e.g., Krause-Jensen et al. 2000), whereas short leaves in hydrodynamically energic environments have been described for other species as a response to avoid high drag forces (e.g., Peralta et al. 2005, 2006; Bouma et al. 2005). The pattern observed for summer and winter seasons, however, seems to be contradictory to many studies that showed long leaves during the summer (e.g., Nienhuis and de Bree 1980; Orth and Moore 1986; Laugier et al. 1999). A plausible explanation is that the seasonality comparison was conducted in a region with very hot summers, where irradiance and temperature may be so high that they may eventually limit the eelgrass growth.

In contrast to morphological acclimation, the responses of leaf mechanical traits of seagrasses to local environmental conditions are not yet well covered (but see Kopp 1999). We found that eelgrass presented more flexible leaves in exposed or shallower locations or during wintertime than those collected in sheltered or deeper locations or during summer season (Fig. 3). Having more flexible 
leaves in exposed, shallower locations or during winter can be interpreted as acclimation strategy to stronger or more frequent forces imposed by waves or currents on plants under those environmental conditions. Being flexible is one of the avoidance strategies in aquatic plants, because flexible leaves bend with the flow reducing the drag forces that they experience (Vogel 1984; Puijalon et al. 2008; Bouma et al. 2005). The mechanical acclimation of seagrass leaves has been previously described for C. nodosa in terms of tensile properties (de los Santos et al. 2013), showing that wave-exposed seagrass leaves presented tougher leaves than leaves of seagrasses from wave-protected locations. Differences in the bending modulus (material property) were only found in the seasonality comparison with leaves being more flexible $\left(2.55 \pm 0.25 \mathrm{~N} \mathrm{~mm}^{2}\right)$ in winter than in summer $(3.77 \pm$ $0.21 \mathrm{~N} \mathrm{~mm}^{2}$ ). This suggests that the observed differences in the flexural rigidity for the other two comparisons (i.e., hydrodynamic exposure and water depth) were caused by changes in leaf thickness and width (Fig. 3), which could be the results of acclimation to other important drivers such as light. Especially, with respect to hydrodynamic exposure (Fig. 3c), this agrees with findings by La Nafie et al. (2012) who did not observe a response of mechanical properties to wave action for Zostera noltei during an 8-week laboratory study. Across climate classes in summer, the contribution of the bending modulus (material property, 35\%) and the leaf thickness (37\%) were similar when investigating the overall variation in eelgrass flexural rigidity among locations (Fig. 4). This differs from properties associated with leaf breaking resistance for seagrass (de los Santos et al. 2013; de los Santos et al. 2016a) and other aquatic plants (Etnier and Villani 2007), where the leaf dimensions (mainly width followed by thickness), and not the leaf strength (material property), determine the leaf breaking resistance when comparing many species. This discrepancy suggests that functional differences between mechanical properties associated with leaf breaking and bending exist.

Flexural rigidity had a negative association with $\mathrm{C}: \mathrm{N}$ ratio content, whereas bending modulus was negatively associated with fibre content. This is partially in accordance with previously reported correlations of mechanical and chemical leaf traits among seagrass species (de los Santos et al. 2012; de los Santos et al. 2016a) or within species (de los Santos et al. 2016b), where traits related to leaf breaking were correlated with $\mathrm{C}: \mathrm{N}$ ratio and fibre content. While those studies showed that the more resistant the leaf to breakage, the higher the $\mathrm{C}: \mathrm{N}$ ratio or the fibre content; here, we observed that the more resistant to be bent (i.e., the higher the flexural rigidity), the lower the $\mathrm{C}: \mathrm{N}$ ratio, and that the more elastic the material in bending (i.e., the lower the bending modulus), the higher the fibre content (Fig. 5). These differences between bending and tensile properties in relation to the leaf fibre and C:N content suggest that a trade-off may exist between fibre and $\mathrm{C}: \mathrm{N}$ ratio in relation to the mechanical 
properties related to bending and tensile deformations. In other words, eelgrass leaves with high contents of structural components (fibres and high $\mathrm{C}: \mathrm{N}$ ) may increase the breaking resistance (tolerance strategy), but may decrease its ability to bend (avoidance strategy-related to flexural rigidity), but still being elastic (related to bending modulus). This avoidance-tolerance trade-off has been previously described for freshwater plants (Puijalon et al. 2011). In addition, not only quantity, but maybe also orientation of the cellulose microfibres within the leaf could be responsible for the variation in the bending properties of seagrasses as found for terrestrial plants (Burgert and Fratzl 2009). The correlation between leaf flexural rigidity and nitrogen content could be attributable to the nitrogen allocated to the cell wall proteins in the fibre bundles.

\section{Conclusions}

We show that the flexural traits of Zostera marina leaves vary significantly along the climate classes of the Atlantic coasts in Europe, implying that temperature could be an important driver in the biomechanics of seagrass leaves. Eelgrass leaves also show acclimation to environmental local conditions in terms of seasonality, water depth, and hydrodynamic exposure. Overall, eelgrass leaves from cold regions presented more elastic and flexible leaves, which were also narrower and with higher fibre content than leaves from plants growing in warmer regions. Within eelgrass populations, the flexural rigidity of the leaves was overall controlled by their material property, the bending modulus, or the leaf thickness. Given the difference to the previous observations, these results suggest functional differences between mechanical properties associated with leaf breaking and bending. To fully understand associated ecological processes, it is thus necessary to consider both tensile and bending properties when assessing seagrass leaf biomechanics.

Leaves of eelgrass collected in exposed or shallower locations or during winter season were more flexible than those collected in sheltered or deeper locations or during summer season, suggesting an avoidance strategy to hydrodynamic forcing, which is generally higher at exposed or shallower locations as well as during winter season. Overall, the high within- and among-location variation in eelgrass morpho-mechanical properties suggests a high acclimating capacity to environmental conditions. Although we did not find the climate driver explaining the variability exhibited in the elasticity and flexural rigidity of Zostera marina leaves along the Atlantic climatic regions in Europe, our findings indicate that this species has a high flexural plasticity and suggest a high acclimation capacity to some climate change effects such as sea level rise (causing a change in depth) and increase in storm frequency and intensity (causing changes in hydrodynamic forcing) (IPCC 2013). 


\section{Acknowledgements}

We are thankful to C. Barañano and E. Fernández-Suárez from the University of Vigo (Spain) and to A. Silva, J. Silva and M. Costa, from the Center of Marine Sciences of Algarve (Portugal), for collecting samples and providing abiotic data. F. Kanzler and the SeaArt team is thanked for collecting the samples in Lübeck bay and E. Infantes assisted in sample collection at the Swedish locations and transport to the Centre of Marine Science of Algarve for further processing. R. Santos is thanked for his kindly financial contribution to the chemical analysis. MP acknowledges funding by the German Science Foundation (Grant No. PA 2547/1-1) and by the Royal Swedish Academy of Sciences (KVA travel grant). This study received Portuguese national funds from FCT_Foundation for Science and Technology through project UID/Multi/04326/2019 and through fellowship SFRH/ BPD/119344/2016 granted to CBS.

\section{Compliance with ethical standards}

Conflict of interest: The authors declare that they have no conflict of interest.

Ethical approval: The collection of seagrass specimen for this study was conducted under permission from the respective authorities. All applicable international, national, and institutional guidelines for the use of plants were followed.

\section{References}

Beck HE, Zimmermann NE, McVicar TR, Vergopolan N, Berg A, Wood EF (2018) Present and future Köppen-Geiger climate classification maps at 1-km resolution. Scientific Data 5:180214

Bouma TJ, de Vries MB, Low E, Peralta G, Tánczos IC, van de Koppel J, Herman PMJ (2005) Trade-offs related to ecosystem engineering: a case study on stiffness of emerging macrophytes. Ecology 86(8):2187-2199

Burgert I, Fratzl P (2009) Plants control the properties and actuation of their organs through the orientation of cellulose fibrils in their cell walls. Integr Comp Biol 49(1):69-79

de los Santos CB, Brun FG, Onoda Y, Cambridge ML, Bouma TJ, Vergara JJ, Pérez-Lloréns JL (2012) Leaffracture properties correlated with nutritional traits in nine Australian seagrass species: Implications for susceptibility to herbivory. Mar Ecol Prog Ser 458:89-102

de los Santos CB, Brun FG, Vergara JJ, Pérez-Lloréns JL (2013) New aspect in seagrass acclimation: Leaf mechanical properties vary spatially and seasonally in the temperate species Cymodocea nodosa Ucria (Ascherson). Mar Biol 160(5):1083-1093

de los Santos CB, Onoda Y, Vergara JJ, Pérez-Lloréns JL, Bouma TJ, La Nafie YA, Cambridge ML, Brun FG, Bouma TJ, La Nafie YA, Cambridge ML, Brun FG (2016a) A comprehensive analysis of 
mechanical and morphological traits in temperate and tropical seagrass species. Mar Ecol Prog Ser 551:81-94

de los Santos CB, Vicencio-Rammsy B, Lepoint G, Remy F, Bouma TJ, Gobert S (2016b) Ontogenic variation and effect of collection procedure on leaf biomechanical properties of Mediterranean seagrass Posidonia oceanica (L.) Delile. Mar Ecol 37(4):750-759

de los Santos CB, Godbold JA, Solan M (2017) Short-term growth and biomechanical responses of the temperate seagrass Cymodocea nodosa to CO2 enrichment. Mar Ecol Prog Ser 572:91-102

Den Hartog C (1970) The sea-grasses of the world. North Holland Publishing Company, Amsterdam

Domke O (2014) Lichtwerte richtig umrechnen. Landwirtschaftskammer Nordrhein-Westfalen. https://www.landwirtschaftskammer.de/gartenbau/beratung/technik/artikel/lichtwerteumrechnen.htm

Etnier SA, Villani PJ (2007) Differences in mechanical and structural properties of surface and aerial petioles of the aquatic plant Nymphaea odorata subsp. tuberosa (Nymphaeaceae). Am J Bot 94(7):1067-1072

Henry P-YT (2014) Bending properties of a macroalga: Adaptation of Peirce's cantilever test for in situ measurements of Laminaria digitata (Laminariaceae). Am J Bot 101(6):1050-1055

IPCC (2013) Summary for policymakers. In: Stocker TF, Qin D, Plattner G-K, Tignor M, Allen SK, Boschung J, Nauels A, Xia Y, Bex V, Midgley PM (eds) Climate change 2013: the physical science basis: contribution of working group I to the fifth assessment report of the intergovernmental panel on climate change. Cambridge University Press, Cambridge and New York

Kopp BS (1999) Effects of nitrate fertilization and shading on physiological and biomechanical properties of eelgrass (Zostera marina L.). Ph.D. Thesis, University of Rhode Island, pp 201

Krause-Jensen D, Middelboe AL, Sand-Jensen K, Christensen PB (2000) Eelgrass, Zostera marina, growth along depth gradients: upper boundaries of the variation as a powerful predictive tool. Oikos 91(2):233-244

Kuo J, Den Hartog C (2006) Seagrass morphology, anatomy, and ultrastructure. In: Larkum AWD, Orth RJ, Duarte CM (eds) Seagrasses: biology, ecology and conservation. Springer, Berlin, pp 51-87

La Nafie YA, de los Santos v, Brun FG, van Katwijk MM, Bouma TJ (2012) Waves and high nutrient loads jointly decrease survival and separately affect morphological and biomechanical properties in the seagrass Zostera noltii. Limnol Oceangr 57(6):1664-1672

La Nafie YA, de los Santos CB, Brun FG, Mashoreng S, van Katwijk MM, Bouma TJ (2013) Biomechanical response of two fast-growing tropical seagrass species subjected to in situ shading and sediment fertilization. J Exp Mar Biol Ecol 446:186-193

Laugier T, Rigollet V, de Casabianca M-L (1999) Seasonal dynamics in mixed eelgrass beds, Zostera marina L. and Z. noltii Hornem., in a Mediterranean coastal lagoon (Thau lagoon, France). Aquat Bot 63(1):51-69

Meling-López AE, Ibarra-Obando SE (1999) Annual life cycles of two Zostera marina L. populations in the Gulf of California: contrasts in seasonality and reproductive effort. Aquat Bot 65(1-4):59-69 Nienhuis 
PH, de Bree BHH (1980) Production and growth dynamics of eelgrass (Zostera marina) in brackish lake Grevelingen (the Netherlands). Neth J Sea Res 14(1):102-118

Niklas KJ (1992) Plant biomechanics: an engineering approach to plant form and function. University of Chicago Press, Chicago

Orth RJ, Moore KA (1986) Seasonal and year-to-year variations in the growth of Zostera marina L. (eelgrass) in the lower Chesapeake Bay. Aquat Bot 24:335-341

Peralta G, Brun FG, Hernández I, Vergara JJ, Pérez-Lloréns JL (2005) Morphometric variations as acclimation mechanisms in Zostera noltii beds. Estuar Coast Shelf Sci 64:347-356

Peralta G, Brun FG, Pérez-Lloréns JL, Bouma TJ (2006) Direct effects of current velocity on the growth, morphometry and architecture of seagrasses: a case study on Zostera noltii. Mar Ecol Prog Ser 327:135-142

Puijalon S, Bouma TJ, van Groenendael J, Bornette G (2008) Clonal plasticity of aquatic plant species submitted to mechanical stress: escape versus resistance strategy. Ann Bot 102(6):989-996

Puijalon S, Bouma TJ, Douady CJ, van Groenendael J, Anten NPR, Martel E, Bornette G (2011) Plant resistance to mechanical stress: evidence of an avoidance-tolerance trade-off. New Phytol 191(4):1141-1149

Read J, Stokes A (2006) Plant biomechanics in an ecological context. Am J Bot 93(10):1546-1565

R Core Team (2018) R: A language and environment for statistical computing. https://www.R-project.org/

Soissons LM, van Katwijk MM, Peralta G, Brun FG, Cardoso PG, Grilo TF, Ondiviela B, Recio M, Valle M, Garmendia JM, Ganthy F, Auby I, Rigouin L, Godet L, Fournier J, Desroy N, Barillé L, Kadel P, Asmus R, Herman PMJ, Bouma TJ (2017) Seasonal and latitudinal variation in seagrass mechanical traits across Europe: The influence of local nutrient status and morphometric plasticity. Limnol Oceanogr 35:269

Troen I, Lundtang Petersen E (1990) Europäischer Windatals. Risø National Laboratory, Roskilde

van Soest PJ, Robertson JB, Lewis BA (1991) Methods for dietary fiber, neutral detergent fiber, and nonstarch polysaccharides in relation to animal nutrition. J Dairy Sci 74(10):3583-3597

Vogel S (1984) Drag and flexibility in sessile organisms. Am Zool 24(1):37-44

WMO (2014) Guide to Meteorological Instruments and Methods of Observation. Geneva, Switzerland, World Meteorological Organization, 1128 pp. (WMO-No.8). http://hdl.handle.net/11329/365 